Dieses Resultat widerspricht nicht der Behauptung von Secchi, Wolf und anderen, nämlich dass beim Maximum der Fleckenthätigkeit die Sonnendurchmesser kleiner sind, als beim Minimum derselben; man muss nur in Betracht ziehen, dass, wie aus den von mir angestellten Beobachtungen erhellt, die Hebung der Sonnenoberfläche an einer Stelle von einer Senkung der angrenzenden Theile der
Oberfläche begleitet wird und dass beim Maximum die sich in mittleren Breiten bildenden Flecke zum grössten Theil die Verkleinerung des sogenannten Horizontaldurchmessers bewirken; während beim Minimum die Flecke sich entweder in niederen oder in höheren Breiten bilden und deswegen meistentheils die Vergrösserung des Horizontaldurchmessers bewirken oder keine Wirkung auf denselben ausüben.

Sternwarte in Charkow 1895 Oct. 26.

F. Sykora.

Vergleichsterne für die Beobachtungen des Faye'schen Cometen 1896

\begin{tabular}{|c|c|c|c|c|c|c|c|c|c|c|c|c|c|c|c|}
\hline $\mathrm{BD}$. & Gr. & & $\alpha \quad 1875.0$ & $\begin{array}{c}\text { Zahl } \\
\mathrm{Bb} .\end{array}$ & Praec. & Var. Saec. & $\delta$ & 1875 & 5.0 & $\begin{array}{c}\text { Zahl } \\
\mathrm{Bb} .\end{array}$ & Praec. & Var. Saec. & Epoche & $\begin{array}{r}\text { Que } \\
\text { Astr. }\end{array}$ & le \\
\hline$-3: 5508$ & 9.2 & & & 2 & $+3^{5} 1013$ & -0.0041 & $-3^{\circ}$ & $4 I^{\prime}$ & $24 " 2$ & 2 & $+r 8.885$ & $+0 . " 144$ & 1873.7 & 84.237 & \\
\hline-4.5764 & 8.5 & 2 & 423 & 2 & $+3.103^{6}$ & -0.0042 & -4 & 2 & 48.7 & 2 & +18.920 & +0.142 & I 873.7 & 82.277 & \\
\hline-3.5536 & 8.3 & 22 & $50 \quad 5^{8.46}$ & I & +3.0987 & -0.0037 & -3 & 49 & I 4.6 & 1 & $+19.15^{2}$ & +0.126 & I 870.8 & 77.266 & $n$ \\
\hline 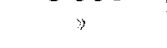 & $»$ & & 58.46 & I & 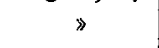 & $»$ & & & 16.0 & I & ( & $»$ & 1873.7 & 85.201 & $»$ \\
\hline-3.5553 & 7.8 & 22 & $28.9 \mathrm{I}$ & 2 & +3.0940 & -0.0033 & -3 & 21 & 26.1 & 2 & +19.265 & +0.117 & & 77.266 & $»$ \\
\hline-3 & 9.0 & 22 & $57 \quad 7.68$ & - & +3 & -0.0031 & -3 & I 3 & 52.0 & - & +1 & 14 & 3.8 & I 12.364 & Ougree \\
\hline-3.5 & 9.2 & 23 & $231.6 \mathrm{I}$ & - & +3. & -0.00 & -3 & 29 & 57.2 & - & +1 & 104 & & I $12.3^{64}$ & $\gg$ \\
\hline-3.5 & 82 & 23 & $239.4^{8}$ & 2 & +3. & -0.0 & -2 & $5^{6}$ & 2.0 & 2 & +1 & 103 & & 82.277 & Leipzig \\
\hline-25 & 8.4 & 23 & I I 51.34 & 6 & +3 . & -0.00 & -2 & 33 & 9.2 & 6 & & & & $69.3^{6} 3$ & Kön. \\
\hline-2.5 & 8.7 & 23 & I 539.01 & - & +3 & -0 & -2 & 30 & 33.8 & - & & 078 & & 109.384 & Pulk. \\
\hline-2.5 & 8.7 & 23 & $22 \quad 37.25$ & $\mathbf{I}$ & +3. & $-c$ & -2 & 9 & 30.7 & $\mathbf{I}$ & $+I$ & .65 & 1884.0 & I I I. I 79 & Berlin \\
\hline-0.4 & $9 \cdot 5$ & 23 & 3231.53 & 2 & +3. & $-0.000 \mathrm{I}$ & -0 & 53 & 22.6 & 2 & +1 & +0.045 & & 86.215 & 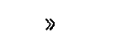 \\
\hline-0.4 & 8.2 & 23 & 3936.01 & 2 & +3 . & +0.0005 & -0 & 25 & 50.4 & 2 & $+r$ & & & 86.215 & 》 \\
\hline-0.4 & $7 \cdot 9$ & 23 & $40 \quad 10.78$ & 2 & +3. & +0.0007 & -0 & 9 & 46.2 & 2 & +19.979 & +0.030 & & 69.79 & $\otimes$ \\
\hline-0.4574 & 9.5 & 23 & $43 \quad 48.92$ & 2 & +3.0725 & +0.0009 & -0 & 9 & $39 \cdot 3$ & 2 & +2 & & & 86.215 & 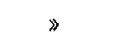 \\
\hline- & 10 & 23 & $\begin{array}{ll}5 \mathrm{I} & 0.80\end{array}$ & 2 & +3.0720 & +0.0015 & +0 & 13 & I 2.2 & 2 & +2 & & & 86.217 & $»$ \\
\hline+0.50 & 9.5 & 23 & 5143.79 & 2 & +3 & +0.00 & +o & I 8 & 7.0 & 2 & +2 & & & 88.29 & $\gg$ \\
\hline+0.5 & 9.0 & 23 & 5336.18 & 2 & +3.0720 & +0.0017 & +0 & 23 & 33.8 & 2 & & +0.004 & & 88.29 & $»$ \\
\hline+0.5080 & 8.8 & 23 & $54 \quad 10.22$ & 2 & +3.0720 & +0.0018 & +0 & 22 & 10.7 & 2 & +20.048 & +0.003 & & 86.217 & \\
\hline+1.35 & 9.0 & $\circ$ & $1 \mathrm{r} \quad 7.8 \mathrm{2}$ & 2 & $+3.074 \mathrm{I}$ & +0.0034 & +1 & 37 & $3^{6.0}$ & 2 & +20.031 & $-0.03 I$ & 1866.9 & 69.67 & 》 \\
\hline
\end{tabular}

Diese Vergleichsterne, deren Oerter auf selbständigen Meridian-Beobachtungen beruhen, habe ich dem Manuscript meines Catalogs von Vergleichsternen, welche in Band 67-1 12 der Astr. Nachr. publicirt worden sind, entnommen. Bei der Reduction auf 1875.0 ist die Struve'sche Praecessionsconstante verwendet.

Schiedam, 1895 Dec. 26.

N.M. Kam.

\title{
Bemerkung zum Aufsatz von Herrn Dr. T. J. J. See
}

"Researches on the orbit of $\Sigma_{21} 73 *$ in A. N. 33 II.

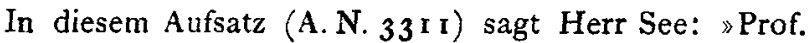
Dunér is the only astronomer who has heretofore attempted to investigate the orbit of this pair «. Im Jahre 1879 aber, in meiner in russischer Sprache unter dem Titel $>$ Ueber die Bahnbestimmung der Doppelsterne« (St. Petersburg r 879) erschienenen Abhandlung sind unter anderen auch die Bahnelemente von $\Sigma 2$ I3 mitgetheilt, welche von mir ausschliesslich nur aus den Beobachtungen von $W$. und $O$. Struve von 1829 bis 1877 berechnet wurden. Diese Elemente stimmten mit den Dunér'schen sehr nahe überein. Ich führe sie hier an und stelle die von Prof. Dunér gefundenen Elemente den meinigen gegenüber.

$$
\begin{aligned}
& \text { Lewitzky } \\
P & =45.35 \text { Jahre } \\
T & =1872.5^{2} \\
e & =0.1145 \\
a & =0.9904 \\
\delta & =152^{\circ} .53 \\
i & =80^{\circ} .76 \\
\lambda & =5^{\circ} .73
\end{aligned}
$$

Dunér 45.43 Jahre $1872.9 \mathrm{r}$ 0.1349 I."009 $152 \% 65$ $80^{\circ} 53$ 7.26

Aus meinen Rechnungen war ersichtlich, dass die damals vorhandenen Beobachtungen des Doppelsterns $\Sigma_{2} 7_{3}$ eine definitive Bestimmung der Bahnelemente noch nicht zuliessen.

Universitätssternwarte Juriew (Dorpat), 1895 Oct. 12.

G. Lewitzky. 